\title{
Bismuth titanate nanoparticles dispersed polyacrylates
}

\author{
Wei-Fang $\mathrm{Su}^{\text {a) }}$ and Jiann-Fong Lee \\ Department of Materials Science and Engineering, National Taiwan University, Taipei, Taiwan \\ Ming-Yao Chen \\ Department of Physics, National Taiwan University, Taipei, Taiwan \\ Ron-Ming Ho \\ Department of Chemical Engineering, National Tsing Hua Univeristy, Hsinchu, Taiwan
}

(Received 25 February 2004; accepted 26 April 2004)

\begin{abstract}
We successfully dispersed amorphous bismuth titanate nanoparticles $(<50 \mathrm{~nm})$ in situ in poly-hydroxy ethyl methacrylate via a sol-gel process. Since less than $20 \%$ of the polymer composition is bismuth titanate by weight, the material exhibits high refractive indices $(>1.6)$ and good optical transparency (>90\% transmittance from 530 to $800 \mathrm{~nm}$ ). Furthermore, this highly cross-linked material has an improved thermal stability and a lower coefficient of thermal expansion than that of neat polymers. The material also displays a high dielectric constant $(>10)$ without ferroelectricity. Thus the material has potential applications in optical lenses, optical waveguides, and capacitors.
\end{abstract}

\section{INTRODUCTION}

Dielectric materials are useful in optical applications and device components such as filters, transmitters, reflectors, lenses, and optical waveguides. They are also utilized widely in electronic devices such as capacitors, actuators, etc. These materials are usually characterized by their refractive indices and dielectric constants. Dielectric materials with high values of refractive indices and dielectric constants can markedly reduce the size of devices, which is highly desirable in integrated circuits, optical systems, electronic systems, and electro-optical systems.

Although polymeric organic materials with good tensile strength and impact resistance can be processed easily at low cost, such materials tend to have low refractive indices and dielectric constants. Correspondingly, though many inorganic materials exhibit both high refractive indices and dielectric constants, they remain difficult to process and are heavy, brittle, and expensive. ${ }^{1}$ Thus, organic/inorganic hybrids have recently emerged as a new class of materials by taking advantage of each species' merits. ${ }^{2-5}$ Currently though, the study of high refractive index and high dielectric constant hybrid materials is limited in the literature.

Bismuth titanate ceramics have been studied widely due to their electro-optical properties, piezoelectricity, ferroelectricity, ionic conductivity, and low sintering

\footnotetext{
a) Address all correspondence to this author. e-mail: suwf@ntu.edu.tw DOI: $10.1557 / J M R .2004 .0312$
}

temperature. Such ceramics are useful in applications such as actuators, capacitors, ${ }^{6}$ nonvolatile memory devices, ${ }^{7}$ microwave filters, ${ }^{8}$ etc. Polyacrylates exhibit high degrees of optical transparency and are good polar dielectrics. Therefore, we expected bismuth titanate nanoparticle dispersed polyacrylate hybrids to have high refractive indices and high dielectric constants. Here, we used a sol-gel process to synthesize the hybrids at molecular levels and studied their optical and electrical properties.

\section{EXPERIMENTAL}

\section{A. Synthesis of polymerizable bismuth titanium 2-methacryl ethoxide}

The synthetic procedures of bismuth titanium 2methacryl ethoxide are modified from our previous reported procedures ${ }^{9}$ and described as follows.

\section{Sodium methoxyethoxide}

Sodium (1.0 g, Aldrich Chemical Company, Milwaukee, WI) and tetrahydrofuran (70.0 g, Fisher Scientific Company, Pittsburgh, PA) were placed in a three-neck reaction flask with stirrer, water condenser and nitrogen purge. Methoxyethanol (3.4 g, Acros Chemical Company, Loughborough, UK) was added into the flask gradually. The reaction was refluxed at $60^{\circ} \mathrm{C}$ until all the sodium reacted. This produced a solution of sodium methoxyethoxide in tetrahydrofuran. By removing the tetrahydrofuran under vacuum at room temperature for $8 \mathrm{~h}$, $\mathrm{NaOC}_{2} \mathrm{H}_{4} \mathrm{OCH}_{3}$ was obtained. The chemical structure of 
the product was identified by ${ }^{1} \mathrm{H}$ nuclear magnetic resonance (NMR; Bruker DMX-200, Rheinstetten, Germany). A $5 \mathrm{wt} \%$ product in $\mathrm{CDCl}_{3}$ with $1 \mathrm{wt} \%$ trimethylsilane internal standard was used for the ${ }^{1} \mathrm{H}$ NMR measurement. Chemical shift peaks were observed at $\delta=3.34,3.37 \mathrm{ppm}\left(\mathrm{CH}_{3}\right) ; 3.45-3.55 \mathrm{ppm}\left(\mathrm{CH}_{2}\right) ; 3.67-$ $3.71 \mathrm{ppm}\left(\mathrm{CH}_{2}\right)$.

\section{Bismuth methoxyethoxide}

First, $4.7 \mathrm{~g}$ bismuth trichloride (Aldrich Chemical Company) was dissolved in $70.5 \mathrm{~g}$ tetrahydrofuran; this solution was added gradually into a flask containing the above sodium methoxyethoxide solution $(74.4 \mathrm{~g})$. The reaction was carried out at $35-40{ }^{\circ} \mathrm{C}$ for $8 \mathrm{~h}$ with stirring and nitrogen purging. The liquid tetrahydrofuran was removed from reaction products by vacuum. Then bismuth methoxyethoxide was obtained by extracting the residue with hexane or isopropyl ether (Aldrich Chemical Company) several times. The extracts were combined and filtered through a $0.5-\mu \mathrm{m}$ filter in a closed system to avoid contact with moisture. Finally, the extracts were dried under vacuum to remove the solvent. This produced a viscous liquid product with $45-80 \%$ yield. The chemical structure of the product was identified by Fourier transform infrared (FTIR; MAGNA-IR550, Madison, WI), ${ }^{1} \mathrm{H}$ NMR (Bruker DMX-200) and ${ }^{13} \mathrm{C}$ NMR (Bruker DMX-200). A 0.05 -g product was placed between two $\mathrm{KBr}$ infrared (IR) plates to prepare IR samples. IR absorption peaks were observed at 2800 $\mathrm{cm}^{-1}$ (aliphatic $\mathrm{C}-\mathrm{H}$ stretching), $1120 \mathrm{~cm}^{-1}$ (ether stretching), and $510-550 \mathrm{~cm}^{-1}$ (Bi-O stretching) and calibrated using polystyrene as a standard. A $5 \mathrm{wt} \%$ product in $\mathrm{CDCl}_{3}$ with $1 \mathrm{wt} \%$ trimethylsilane internal standard was used for ${ }^{1} \mathrm{H}$ NMR and ${ }^{13} \mathrm{C}$ NMR measurements. The ${ }^{1} \mathrm{H}$ NMR chemical shift peaks were observed at $\delta=3.34$ and $3.37 \mathrm{ppm}\left(\mathrm{CH}_{3}\right) ; 3.45-3.55 \mathrm{ppm}\left(\mathrm{CH}_{2}\right)$; 3.67-3.71 ppm $\left(\mathrm{CH}_{2}\right)$. The chemical shift peaks under ${ }^{13} \mathrm{C}$ NMR were observed at 58.402 and $58.808 \mathrm{ppm}$ $\left(\mathrm{CH}_{3}\right) ; 62.184,62.254$, and $62.909 \mathrm{ppm}\left(\mathrm{CH}_{2}\right) ; 71.396$ and $77.205 \mathrm{ppm}\left(\mathrm{CH}_{2}\right.$, close to $\left.\mathrm{Bi}-\mathrm{O}\right)$. The product was stored in tetrahydrofuran as a $3 \%$ solution for long-term stability.

\section{Bismuth titanium 2-methacryl ethoxide}

In a dry nitrogen glove box, $100 \mathrm{ml}$ sodium dried tetrahydrofuran and $10.33 \mathrm{~g}$ titanium n-propoxide (Aldrich Chemical Company) were placed in a $250-\mathrm{ml}$ flask and thoroughly mixed at room temperature for $30 \mathrm{~min}$. Then 18.73 g hydroxy ethyl methacrylate (Aldrich Chemical Company) were added into the mixture and reacted at room temperature. As soon as the solution became golden yellow, vacuum distillation at room temperature was used to remove any propanol byproduct. Distillation was continued for $12 \mathrm{~h}$ to remove tetrahydrofuran and propanol completely. From this, solventless titanium methacryl ethoxide was obtained. Then in a dry nitrogen glove box, $1.5 \mathrm{~g}$ titanium methacrylate ethoxide (prepared previously), $8.16 \mathrm{~g}$ hydroxy ethyl methacrylate, and 2-3 drops water were mixed for $10 \mathrm{~min}$ in a flask. Following this, $13.5 \mathrm{~g} 1.7 \times 10^{-4} \mathrm{~mol}$ bismuth methoxy ethoxide in tetrahydrofuran was added into the mixture and refluxed at $60{ }^{\circ} \mathrm{C}$ for $1 \mathrm{~h}$. Vacuum distillation was used to remove tetrahydrofuran and methoxy ethanol by-product at room temperature for $8 \mathrm{~h}$. The resulting product was a solventless titanium bismuth methacryl ethoxide. The chemical structure of this product was identified by FTIR (MAGNA-IR550). A 0.05-g product was placed between two KBr IR plates to prepare an IR sample. IR absorption peaks were observed at 655 , 593, 526 and $487 \mathrm{~cm}^{-1}$ for Ti-O and $\mathrm{Bi}-\mathrm{O}$ stretching with polystyrene used as a calibrating standard.

\section{B. Preparation of ultraviolet polymerized samples}

The test samples of hybrid material and neat polymer were prepared using ultraviolet light induced free radical polymerization of acrylate monomer [ultraviolet (UV) polymerization].

Three samples with molar ratios of Bi:Ti:acrylate (1) $0.37: 1: 8$, (2) $0.56: 1: 8$, (3) $0.74: 1: 8$ (equivalent to 13.3 , 16.2 , and $18.9 \mathrm{wt} \%$ oxides) were prepared and labeled as poly hydroxy ethyl methacrylate (PHEMA)/bismuth titanate-1, -2 , and -3 respectively. Aqueous hydroxy ethyl methacrylate (about $2 \mathrm{~g}$, containing $10 \mathrm{wt} \% \mathrm{H}_{2} \mathrm{O}$ ) was added to a mixture of $9.96 \mathrm{~g}$ polymerizable bismuth titanium 2-methacryl ethoxide and $0.04 \mathrm{~g}$ photoinitiator, 2,2-dimethoxy-2-phenyl acetophenone (Ciba-Geigy, Basel, Switzerland) to hydrolyze the precursor. The volume of water used was half the amount that was required to gel the precursor mixture. The precursor mixture was poured into various Teflon molds to make samples with different thickness ranging from $20 \mu \mathrm{m}$ to $2 \mathrm{~mm}$. Next, the precursor mixture was hydrolyzed in the mold for $24 \mathrm{~h}$ at room temperature. Following hydrolysis, the sample was placed under a UV light at a distance of $0.5 \mathrm{~cm}$ (UVP Co., Upland, CA, Model UVGL-25; intensity $1200 \mu \mathrm{W} / \mathrm{cm}^{2}$ ) and irradiated at $254 \mathrm{~nm}$ for $3 \mathrm{~min}$ and $365 \mathrm{~nm}$ for $3 \mathrm{~min}$.

The neat polymer (PHEMA) was made by casting followed by UV polymerization of a mixture containing $9.96 \mathrm{~g}$ hydroxy ethyl methacrylate and $0.04 \mathrm{~g} \mathrm{2,2-}$ dimethoxy-2-phenyl acetophenone on glass or quartz substrates. The polymerization conditions were the same as those for that of the hybrid material described above.

\section{Characterization of polymerized samples}

The cross-linking density of the material was determined using the percent extract obtained from the polymerized sample after refluxing it in dimethyl formamide for $24 \mathrm{~h}$ according to the procedure of ASTM D2765. ${ }^{10}$ 
A 1-g sample was used for the test. For each material, the percent extract was the average test value of three different samples.

An ellipsometer (SOPRA, GES5, Paris, France) was used to evaluate the refractive indices of the materials in the wavelengths ranging from 400 to $800 \mathrm{~nm}$. The sample for the ellipsometer measurement was a $20-\mu \mathrm{m}$ film of material casted on the glass substrate. An UVvisible spectrophotometer (Thermo Electron Co. He $\lambda$ ios Gamma Series, Waltham, MA) was used to study the optical transparency of the materials from 300 to $800 \mathrm{~nm}$. The sample for the optical transparency measurement was a $40-\mu \mathrm{m}$ film of material prepared on quartz substrate. The thermal stability of the materials was determined by monitoring the percent weight loss upon heating using thermogravimetric analysis (TGA; DuPont 9900, Newcastle, PA, TGA 954). A 0.1-g sample was heated at $10{ }^{\circ} \mathrm{C} / \mathrm{min}$ from 70 to $700{ }^{\circ} \mathrm{C}$ in nitrogen by TGA. The coefficient of thermal expansion of material was determined by monitoring the dimension change upon heating using thermal mechanical analyzed (TMA) (TA Instrument TMA 2940, Newcastle, PA). A sample 5 $\times 5 \times 2 \mathrm{~mm}$ (width $\times$ length $\times$ thickness) was heated at 10 ${ }^{\circ} \mathrm{C} / \mathrm{min}$ from 70 to $200{ }^{\circ} \mathrm{C}$ in air by TMA. Dispersion and sizes of bismuth titanate in polymer was analyzed by transmission electron microscopy (TEM; Hitachi H-7100 TEM instrument, Tokyo, Japan). The TEM sample was prepared by microtoming bulk material into film a few nanometers in thickness. The film was coated with a few nanometers of carbon coating to dissipate charge on the material and carried by copper grit for the TEM measurement. Crystalline behavior of the material was examined by x-ray diffraction (XRD; Philips PW1830 X-ray diffractor, Eindhoven, The Netherlands) with $\mathrm{Cu} \mathrm{K}_{\alpha}$ wavelength of $2 \theta=10^{\circ}$ to $90^{\circ}$ at a scan rate of $10^{\circ} / \mathrm{min}$ A few grams of film or powdered samples were used for XRD measurements. The dielectric constants of samples were measured using a Wayne Kerr Precision Magnetics Analyzer PMA 3260A (Chichester, UK) at $25{ }^{\circ} \mathrm{C}$ from 100 to $2 \times 10^{6} \mathrm{~Hz}$. A $20 \mathrm{~mm}$ diameter $\times 2 \mathrm{~mm}$ sample size with a 15 -mm-diameter silver paste electrode was used for dielectric measurements. Ferroelectricity of the samples $(10 \times 10 \times 2 \mathrm{~mm}$ sample size $)$ was measured at voltages from 5 to $20 \mathrm{~V}$ using a Radiant Technologies RT-66A (Albuquerque, NM).

\section{Preparation of bismuth titanate sol-gel powder for dielectric constant measurements}

A mixed alkoxide solution with a 1:0.74 molar ratio of $\mathrm{Ti}$ to $\mathrm{Bi}$ was obtained by mixing required amount of bismuth methoxy ethoxide (3\% in tetrahydrofuran obtained as above) and titanium butoxide. A $10 \mathrm{wt} \%$ aqueous tetrahydrofuran solution was added gradually to the alkoxide mixture solution until a gel was formed. This gel was dried at $120{ }^{\circ} \mathrm{C}$ for 3 days. The dried gel was mortar ground into powder and cold pressed at $42 \mathrm{MPa}$ to make a 10 -mm-diameter $\times 2$-mm-thick disk for dielectric measurements. Scanning electron microscope measurements (SEM; JSM-T100, Joel, Japan) of the disk cross sections revealed that gel particle sizes ranged from approximately 20 to approximately $100 \mu \mathrm{m}$.

\section{RESULTS AND DISCUSSION}

We used a sol-gel process to prepare organicinorganic hybrid materials via in situ formation of inorganic nanoparticles in an organic matrix. Bismuth titanium 2-methacryl ethoxide was first synthesized as a precursor of the hybrid materials. Bismuth titanate nanoparticles were formed in situ in the hydroxy ethyl acrylate monomer during hydrolysis of precursors. Then the nanoparticles containing acrylate monomers were polymerized by UV light to obtain the hybrid materials. The monomer has unsaturated acrylate double bonds that can be polymerized by photo-induced free radical polymerization. UV is an inexpensive photo source which has been used extensively in this type of polymerization (UV polymerization). ${ }^{11}$ Resulting hybrid materials with three bismuth titanate compositions (13.3, 16.2, and $18.9 \mathrm{wt} \%)$ were prepared and labeled as PHEMA/bismuth titanate1, PHEMA/bismuth titanate-2 and PHEMA/bimuth titanate- 3 respectively. The chemical reactions involved in this process are described in Scheme 1.

Using this process, bismuth titanate nanoparticles less than $50 \mathrm{~nm}$ in size are well dispersed in the polyacrylate as shown in the TEM photo of the PHEMA/bismuth titanate-1 sample (Fig. 1). A clear 2-mm-thick sample (PHEMA/bismuth titanate-2) was obtained, indicating good visible light transparency of the material (Fig. 2). Good optical transmittance ( $>90 \%$ from 530 to $800 \mathrm{~nm}$ ) of approximately $40-\mu \mathrm{m}$-thick films of these three samples (Fig. 3) means that the bismuth titanate particles were well dispersed in the polymer matrix without any agglomeration. The transmittance of the films was decreased slightly with increasing amounts of bismuth titanate. The bismuth titanate nanoparticles in the hybrid

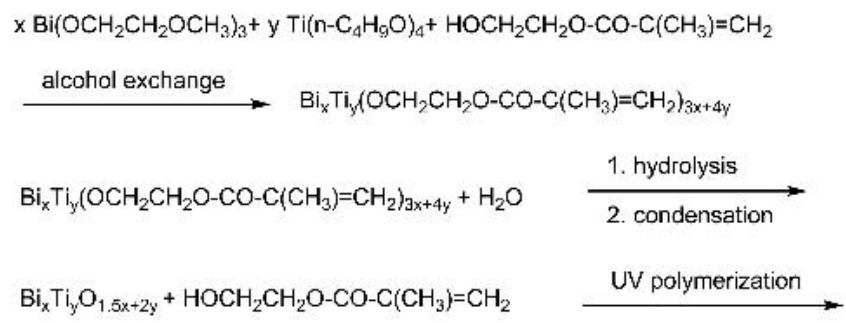

crosslinked bismuth titanate polyacrylate

SCHEME 1. Preparation of bismuth titanate nanoparticles dispersed polyacrylate hybrid. 


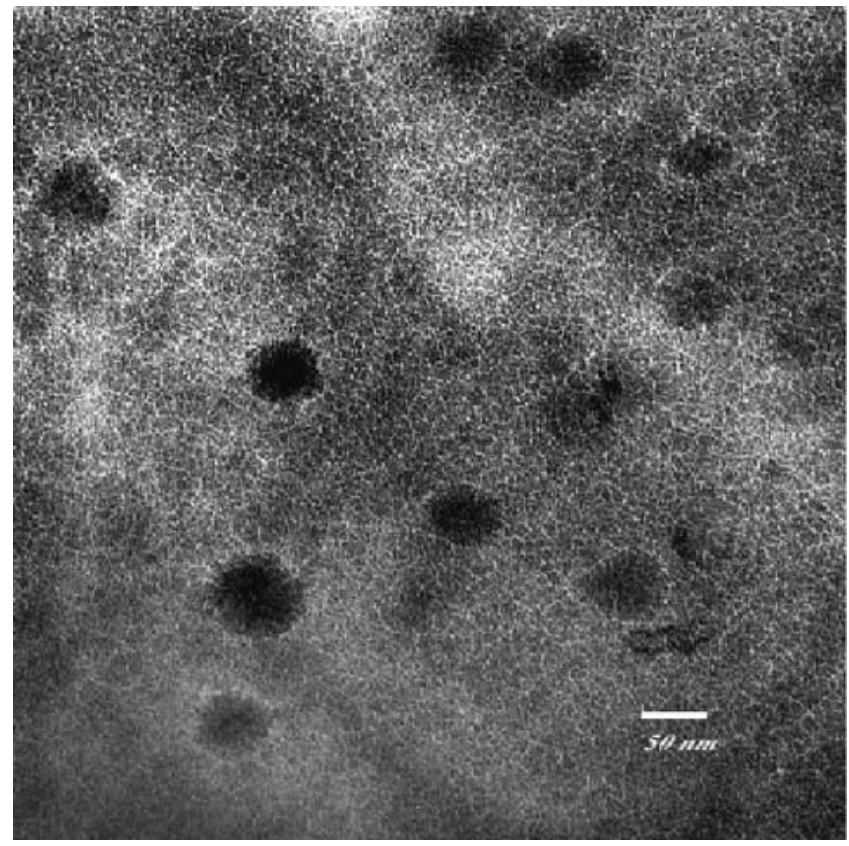

FIG. 1. TEM photo of PHEMA/bismuth titanate-1 shows that the size of the bismuth titanate nanoparticles is about $20-50 \mathrm{~nm}$.

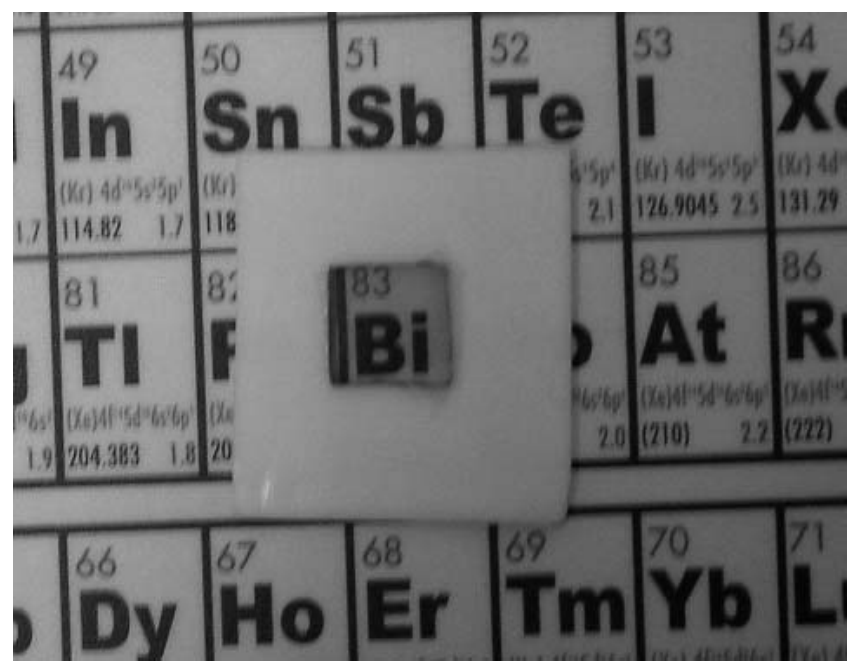

FIG. 2. PHEMA/bismuth titanate-2 shows good transparency in visible light (UV cured sample overlies the Bi symbol).

may serve as scattering centers which reduce the transmittance of hybrid material. Refractive indexes of the neat polymers increases with the presence of bismuth titanate nanoparticles. This amount increases proportionally with the amount of bismuth titanate (Fig. 4). Such results are expected due to the high refractive index of the inorganic material. Furthermore, the highly crosslinked structure of our materials would increase the density of material that results in increasing refractive index (as discussed below).

Our material does not dissolve in acetone and swells in $\mathrm{N}$-methyl pyrrolidone indicating a possible crosslinked

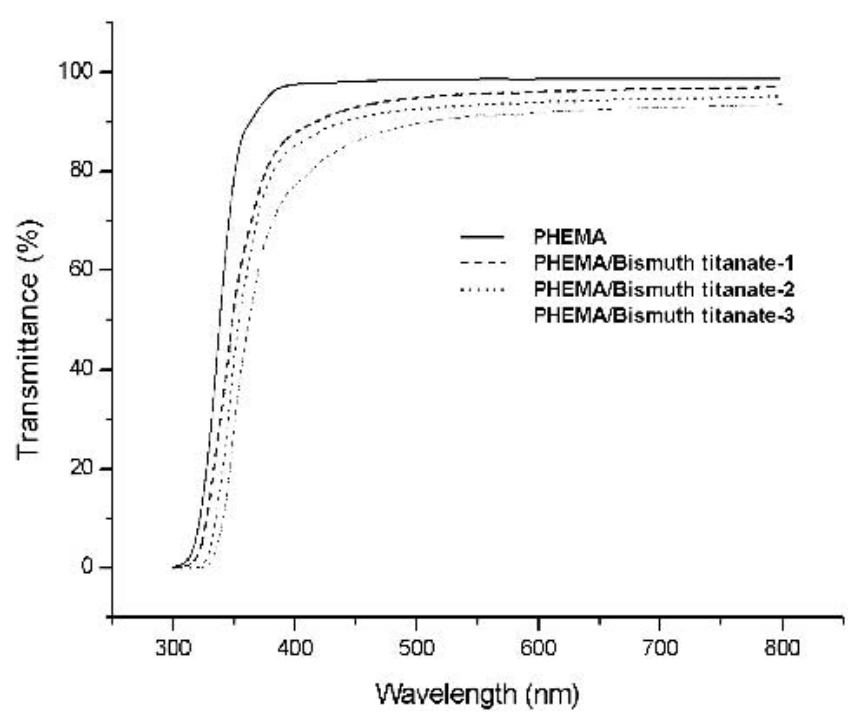

FIG. 3. Optical transmission spectra of bismuth titanate polyacrylates as compared with neat polymer. The hybrid materials with a thickness of about $40 \mu \mathrm{m}$ have good optical transparency from 300 to $800 \mathrm{~nm}$.

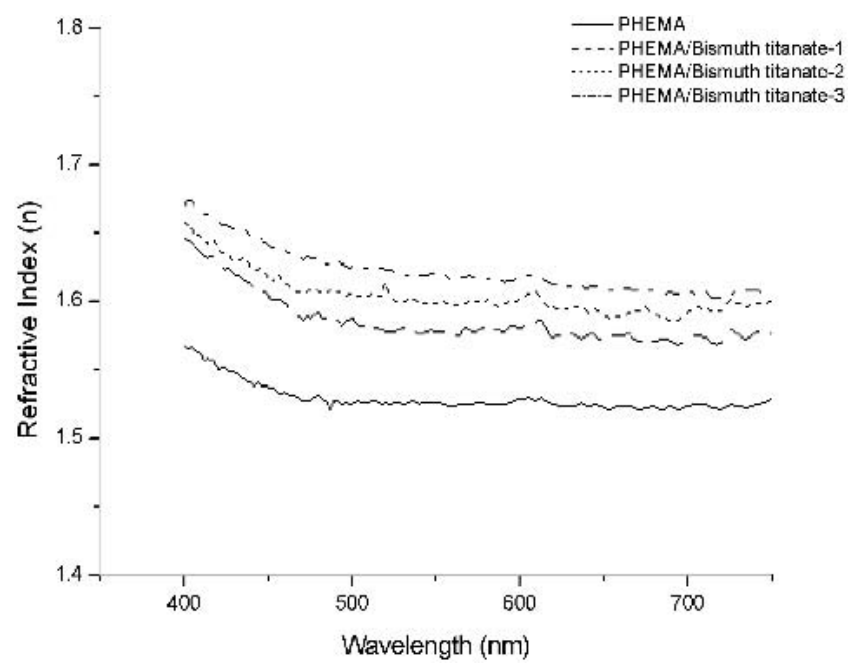

FIG. 4. Refractive indices spectra of bismuth titanate polyacrylates. The hybrid materials have high refractive indices from 400 to $800 \mathrm{~nm}$.

TABLE I. Results of swell ratio and percent extraction of bismuth titanate polyacrylates. The hybrid materials show low percent extraction and high crosslinking density.

\begin{tabular}{lcc}
\hline \hline \multicolumn{1}{c}{ Sample } & Swell ratio & Percent extract \\
\hline PHEMA & 13.988 & 37.849 \\
PHEMA/Bismuth titanate-1 & 1.417 & 9.581 \\
PHEMA/Bismuth titanate-2 & 1.371 & 8.291 \\
PHEMA/Bismuth titanate-3 & 1.205 & 7.592 \\
\hline \hline
\end{tabular}

structure. The extent of crosslinking was determined by measuring the amount of extract from the samples resulted from reflux in dimethyl formamide for $24 \mathrm{~h}$. Samples with higher concentrations of bismuth titanate exhibited a higher degree of crosslinking, as shown in 


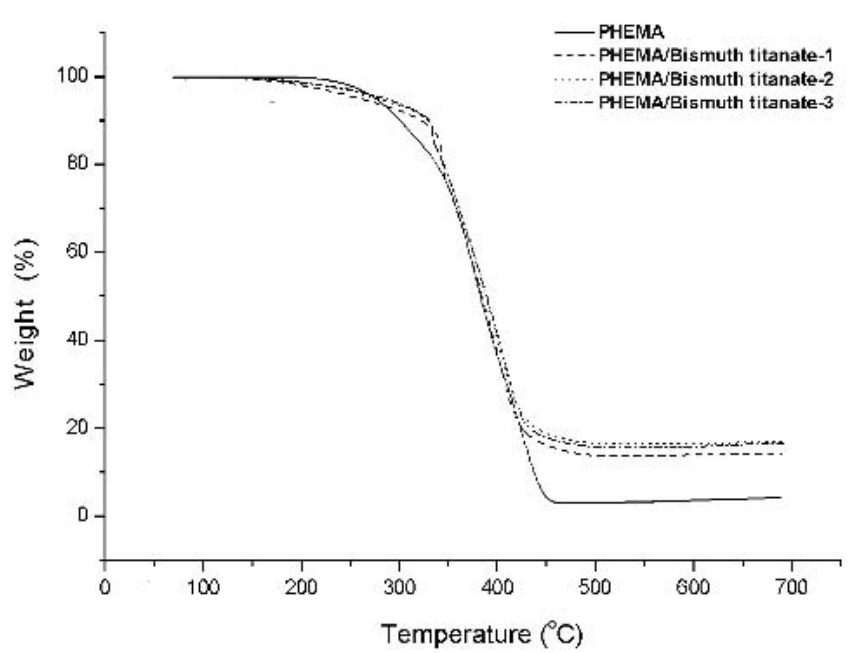

FIG. 5. TGA results of bismuth titanate polyacrylates as compared with neat polyacrylate. The hybrid materials have greater thermal stability.

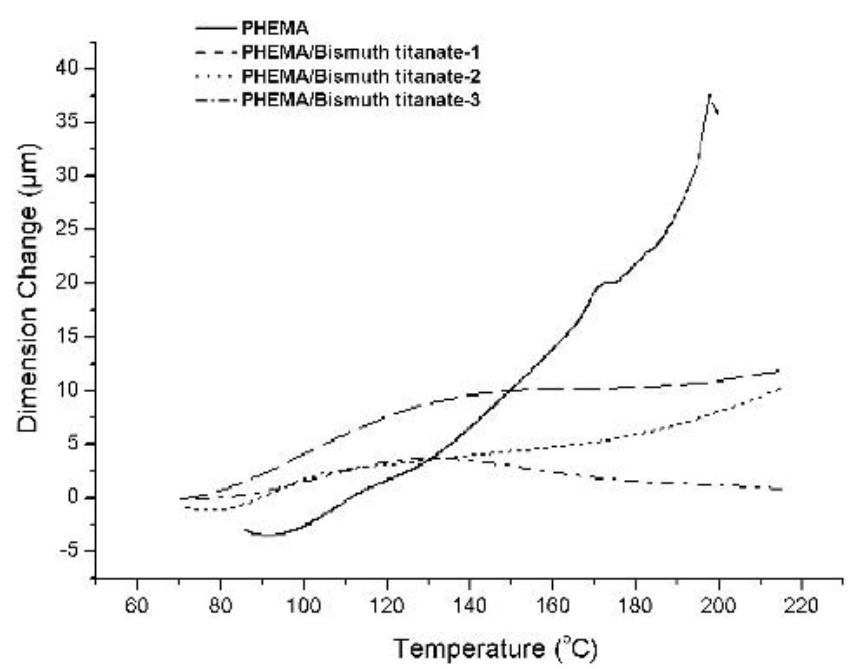

FIG. 6. TMA results of bismuth titanate polyacrylates as compared with neat polyacrylate. The hybrid materials exhibit a lower coefficient of thermal expansion than that of neat polymer.

Table I. Such results may be due to the provision of more crosslinking sites by bismuth titanate compared to those of acrylate monomers. Highly crosslinked structure of hybrids improves the thermal stability ( $\sim 340$ versus $300{ }^{\circ} \mathrm{C}$ at $10 \%$ weight loss) and lowers coefficients of thermal expansion $\left(\sim 100\right.$ versus $\left.307 \mu \mathrm{m} / \mathrm{m}{ }^{\circ} \mathrm{C}\right)$ compared to neat polymer (Figs. 5 and 6). These results are consistent with previous reports on hybrid materials. ${ }^{12}$ Polymers usually exhibit higher coefficients of thermal expansion (CTE) than ceramic materials due to the high free volumes of polymers. Polymer-free volume can be very effectively reduced by crosslinking polymer chains. ${ }^{10}$ In our hybrid material, we have a crosslinking structure that contains ceramic material to reduce free volume. Thus, a lower CTE is expected from the hybrid material as compared with to neat polymer.

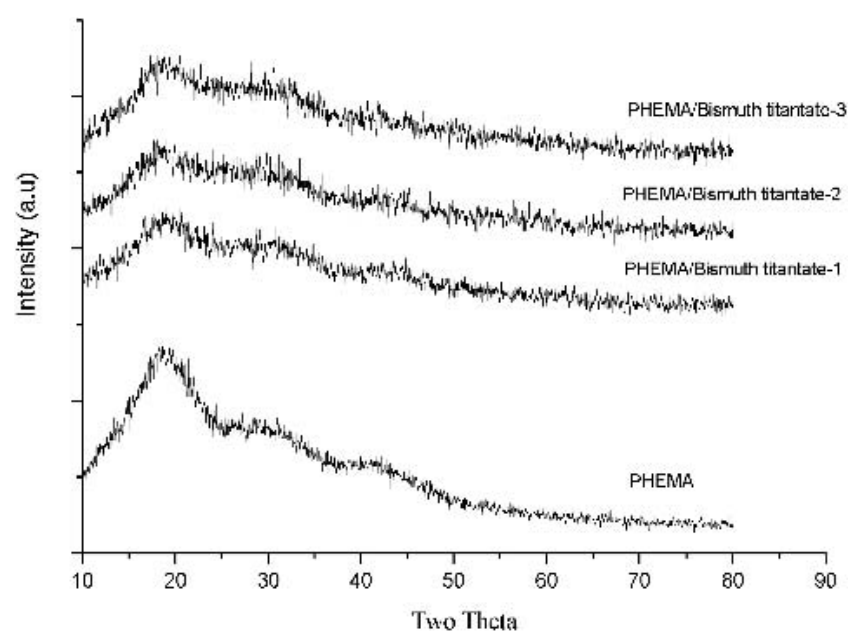

FIG. 7. X-ray diffraction patterns of bismuth titanate polyacrylates as compared with those of neat polyacrylate. The hybrid materials show less-ordered structures than that of neat polymers.

Figure 6 also shows that the CTE of hybrid material decreases with an increasing bismuth titanate concentration. The curvatures in the plot of CTE versus. temperature are not clear this time and currently under investigation.

X-ray diffraction studies show the samples to be amorphous and less structured than that of neat polymer (Fig. 7). The presence of the bismuth titanate phase in the polymer decreases the chain folding and hydrogen bonding from the hydroxy ethyl group of the acrylate, thus resulting in a less orderly structure.

Compared with the neat polymer $\left(\varepsilon_{\mathrm{r}}=4.5\right.$ at $1 \mathrm{KHz}$. $)$, the dielectric constant of the material is more than double with the addition of less than $20 \mathrm{wt} \%$ bismuth titanate (Fig. 8). The pure bismuth titanate (molar ratio Bi:Ti $=$

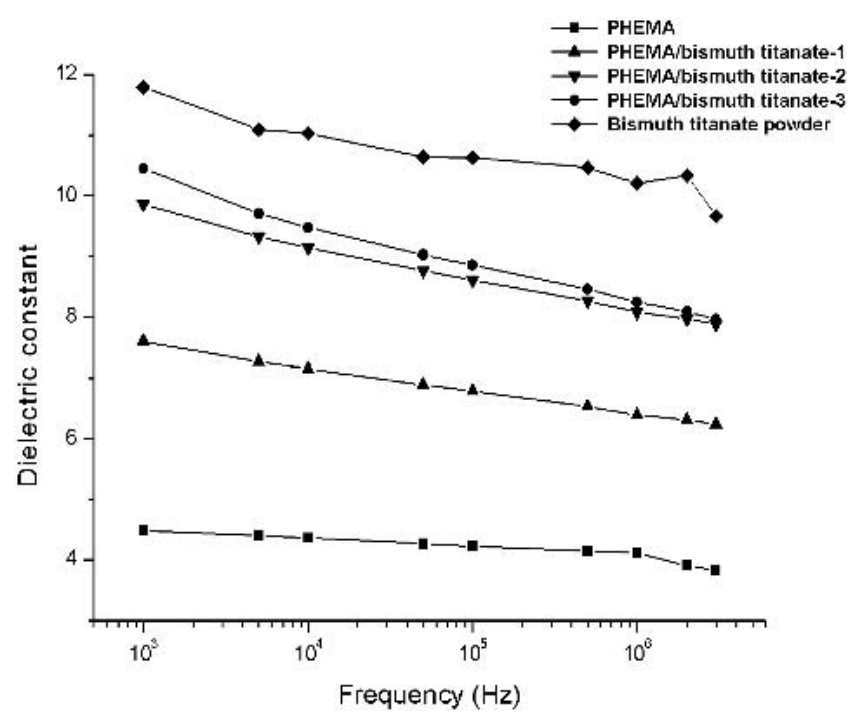

FIG. 8. Dielectric measurements of bismuth titanate polyacrylates as compared with polyacrylate and bismuth titanate. The hybrid materials exhibit higher dielectric constants from $1 \mathrm{KHz}$ to $2 \mathrm{MHz}$. 
0.74:1.00) powder was prepared by sol-gel process. The powder was pressed into a disk for dielectric constant measurements. This material exhibited a dielectric constant $\epsilon_{\mathrm{r}} \sim 12$ at $1 \mathrm{KHz}$. The hybrid sample PHEMA/ bismuth titanate-3 contains 18.9 wt $\%$ bismuth titanate and exhibited a dielectric constant of 10.4. This is higher than predicted by the simple addition rule $(\sim 5.92)$. If the pure bismuth titanate is $50 \%$ porous, its dielectric constant should be 23 . This would give a dielectric constant about 8.00 instead of the observed value of 10.4 using the addition rule. Such a high-dielectric constant of the hybrid material may be due to effective nanoscale interactions between the organic phase and inorganic phase under an electric field. Ferroelectric behavior was not observed in the hybrid materials, possibly due to the amorphous structure of bismuth titanate.

\section{CONCLUSION}

Amorphous bismuth titanate nanoparticles dispersed in polyacrylates exhibit high dielectric constants and high refractive indices. We prepared them via a sol-gel process using polymerizable titanium bismuth methacryl ethoxide precursors. The material exhibits good optical transparency and low optical dispersion. It also has excellent thermal and dielectric properties. Insomuch, the material has many potential applications in optical lenses, optical waveguides, and capacitors.

\section{ACKNOWLEDGMENTS}

The authors of this paper would like to thank the National Science Council of Republic of China under Grant Nos. NSC 91-2120-E-002-011 and 92-2120-E-002-001 and the Ministry of Economic Affairs under Grant No.
91-EC-17-A-08-S1-0015 for financial support of this research. Thanks are also due to Dr. L.C. Scala and Mr. An-Jey Su for helping to prepare this manuscript.

\section{REFERENCES}

1. D.R. Askeland: The Science and Engineering of Materials, 3rd ed. (PWS Publishing Company, Boston, MA, 1994), pp. 630-634.

2. P. Judeinstein and C. Sanchez: Hybrid organic-inorganic materials: A land of multidisciplinary. J. Mater. Chem. 6, 511 (1996).

3. L.H. Lee and W.C. Chen: High-refractive-index thin films prepared from trialkoxysilane-capped poly(methyl methacrylate)titania materials. Chem. Mater. 13, 1137 (2001).

4. Q.R. Huang, W. Volksen, E. Huang, C.W. Frank, and R.D. Miller: Structure and interaction of organic/inorganic hybrid nanocomposites for microelectronic applications. 1. MSSQ/P(MMA-co-DMAEMA) nanocomposites. Chem. Mater. 14, 3676 (2002).

5. W.X. Que, X. Hu, and Q.Y. Zhang: Preparation and optical of patternable $\mathrm{TiO}_{2}$ /ormosils hybrid films for photonics application. Chem. Phys. Lett. 369, 354 (2003).

6. T. Yogo, K.I. Kikuta, S. Yamada, and S.I. Hirano: Synthesis of barium titanate/polymer composites from metal alkoxides. J. Sol.-Gel Sci. Technol. 2, 175 (1994).

7. T. Nakamura, R. Huhammet, M. Shimizu, and T. Shiosaki: Preparation of $\mathrm{Bi}_{4} \mathrm{TiO}_{3} \mathrm{O}_{12}$ films by MOCVD and their applications to memory devices. Integrated Ferroelectrics 6, 35 (1995).

8. K. Fukuda, R. Kitoh, and I. Awei: Microwave characteristics of $\mathrm{TiO}_{2}-\mathrm{Bi}_{2} \mathrm{O}_{3}$ dielectric resonator. Jpn. J. Appl. Phys. 32, 4584 (1993).

9. W.F. Su and H.K. Yuan, Solventless nontoxic high refraction indices and low birefringence organic/inorganic hybrid materials, U.S. Patent No. 6492540 (2002).

10. Standard test method for determination of gel content and swell ratio of crosslinked ethylene plastics, ASTM International, West Conshohocken, PA, 1995.

11. G. Odian: Principles of Polymerization, 3rd Ed. (John Wiley \& Sons, Hoboken, NJ, 1991).

12. E.P. Giannelis: Polymer layered silicate nanocomposites. Adv. Mater. 8, 29 (1996). 